Article

\title{
Study of Enhanced Oil Recovery and Adsorption Using Glycerol in Surfactant Solution
}

\author{
Fabiola D. S. Curbelo*(D, Alfredo Ismael C. Garnica, Danilo F. Q. Leite, Amanda B. Carvalho, \\ Raphael R. Silva and Evanice M. Paiva
}

Federal University of Paraiba, João Pessoa, Paraíba 58000-000, Brazil; alfredocurbelo@yahoo.com (A.I.C.G.); eng.danilo.ufcg@gmail.com (D.F.Q.L.); amandabritodecarvalho@outlook.com (A.B.C.);

ribeiro.rse@gmail.com (R.R.S.); evanice.medeiros@hotmail.com (E.M.P.)

* Correspondence: fabioladias@yahoo.com; Tel.: +55-83-99613-8786

Received: 13 May 2020; Accepted: 8 June 2020; Published: 17 June 2020

check for updates

\begin{abstract}
Over time, oil production in a reservoir tends to decrease, which makes it difficult to flow through the reservoir to the well, making its production increasingly difficult and costly. Due to their physical properties, such as reducing the water/oil interfacial tension, surfactants have been used in enhanced oil recovery (EOR) processes, however, their adsorption presents as an undesirable and inevitable factor and can decrease the efficiency of the method. This work's main objective is to evaluate the effect of glycerol in the adsorption of surfactants in sandstones, as well as in the recovery factor during EOR. Brine solutions containing the nonionic surfactant saponified coconut oil (SCO), with and without glycerol, were used in the adsorption and oil recovery tests in sandstone. Adsorption, recovery, rheological, and thermogravimetric analysis were carried out. Regarding the surfactant/glycerol/brine solution, there was an improvement in the oil mobility, as the glycerol contributed to an increase in the viscosity of the solution, thereby increasing the sweep efficiency. The recovery factor obtained for the surfactant solution with glycerol was satisfactory, being $53 \%$ higher than without glycerol, because it simultaneously provided an increase in viscosity and a decrease in interfacial tension, both of which are beneficial for the efficiency of the process.
\end{abstract}

Keywords: saponified coconut oil; glycerol; surfactant flooding; adsorption; enhanced oil recovery

\section{Introduction}

The oil reservoir's production time is divided in conventional recovery and enhanced recovery. In conventional recovery, it is observed that the formation's own energy, combined with the pumping of fluids without any chemical reaction with the reservoir's oil, is applied in extraction. While, in enhanced oil recovery, particular mechanisms take place, in order to partially maintain the formation's energy. Enhanced oil recovery (EOR) aims to further increase the recovery factor by injecting displacing fluids to modify the formation's conditions and displacement mechanism [1-3].

In conventional oil recovery processes, water or natural gas is used as the injection fluid. The injected water can be aquifer water, collected in subsurface springs through wells drilled for this purpose; surface water, collected in rivers, lakes, etc.; seawater; or water that is a naturally occurring byproduct in extraction. However, before being injected, the water must be subjected to a treatment, in order to make it more suitable for the reservoir and the fluids in it $[4,5]$.

In studies done to increase oil recovery (enhanced oil recovery (EOR)), several methods of advanced oil recovery are used. In some, only the formation's pressure is used to increase recovery, others use the water injection process, and, in others, miscible techniques are the most used.

The EOR methods aim to improve two limiting aspects of recovery: the viscosity of the injected fluid and the high interfacial tension between the reservoir's fluids [5]. If there is a high discrepancy 
between the viscosities of the injected and displaced fluids, the first will be automatically moved more easily, generating preferential paths in the porous medium and moving quickly into the production wells. Therefore, the injected fluid does not properly sweep the reservoir, leaving large volumes of the porous medium, where the displacement is not processed [3,5].

In the case of high interfacial tension, the potential of the injected fluid to remove reservoir oil from the porous medium is very low, leaving large amounts of oil where the injected fluid has already been in contact, thus resulting in low displacement efficiencies. The interfacial tension, of physical-chemical nature plays an important role in the interactions between rock and fluids, having variable intensity, according to the type of the components [5].

The application of surfactants in EOR has been widely used, since it presupposes a certain chemical reaction between the injected fluids and the reservoir's fluids. The surfactant has the purpose of reducing the interfacial tensions between water (brine) and oil, which is a thermodynamically fundamental property of an interface, increasing the displacement efficiency, due to the fact that the interfacial tension is a measure of miscibility [4,5]. Unlike the injection of immiscible fluids, which present a purely mechanical displacement behavior with fewer recovery factors, due to the presence of high interfacial tensions.

One way to solve the problems of low sweep efficiencies-due to the difference in viscosity of the injected and displaced fluids-and of the high interfacial tensions found in EOR processes, can be the use of surfactant solutions and viscosifying agents as displacing fluids.

Polymer flooding is an enhanced oil recovery method that uses polymer solutions in the displacement of water to decrease the water/oil mobility ratio [6], however, they only act on the viscosity of the displacing fluid. The combined use of surfactant and glycerol represents an attractive method because they can simultaneously provide an increase in water viscosity, and a decrease in interfacial tension, both of which are beneficial for the efficiency of the process.

Surfactants interact among themselves through the formation of micelles in the solution, and their adsorption in the reservoir is a problematic situation, because a reduction in their concentration could lead to a decrease in the EOR efficiency [7-11].

Glycerol, IUPAC name Propane- 1, 2, 3 triol, has been integrated in industrial processes like foods and beverages, cosmetics, medicines, oil, and as lubricants for the maintenance of equipment in industrial plants. In oil reservoirs, especially in EOR, its viscosity can help to obtain higher production factor [12-14]. Hence, the addition of glycerol in surfactant solution presents as a technological strategy to achieve better enhanced oil recovery, causing the injected fluid to move in the porous medium with the same mobility as the oil $[15,16]$. The glycerol acts as a viscosifier agent and the surfactant ensures low interfacial (IFT) and superficial (ST) tension.

This work proposes to study the effect of glycerol in surfactant solutions, on adsorption, and in enhanced oil recovery. For this, saponified coconut oil surfactant solutions with and without glycerol were used.

\section{Materials and Methods}

Saponified coconut oil was used as the surfactant, due to its better adsorption/recovery results compared to nonionic and cationic surfactants studied by [17]. The ionic surfactant was synthesized in the laboratory, following the methodology described by [18]. The solutions were prepared with distilled water, at a concentration of $2 \mathrm{wt}$. \% $\mathrm{KCl}$ (P. A. Alphatec Ltd.a), with and without glycerol (Neon Comercial Ltd.a, purity $99.70 \%$ ).

\subsection{Surfactant Solutions Properties}

In order to determine the critical micelle concentration (CMC) of the surfactants, surface tension $(\tau)$ measurements were taken of different concentrations of surfactant solutions, with and without glycerol, at room temperature of $26^{\circ} \mathrm{C}$ [19] by the Superficial Tension apparatus, SensaDyne/QC6000. 
The surfactant and $\mathrm{KCl}(2 \mathrm{wt}$. \%) solution was used for both the glycerol-free and glycerol solutions $(20 \% w / v)$.

The $2 \mathrm{wt}$. \% $\mathrm{KCl}$ concentration was used to verify the better interaction of the displacing fluid solution with the reservoir's rock, since the reservoir water presents salinity, and this interferes with the CMC value of the surfactant by the competition of salt with the hydrophilic group of surfactants in water solubility, as well as rock wettability [10,20-23].

The concentration of $20 \%$ by volume of glycerol was used, so that the solution presented a viscosity close to oil viscosity, guaranteeing a favorable mobility ratio for EOR.

\subsection{Adsorption Test}

The adsorbent used was the crushed sandstone, from Botucatu region, Paraná/Brazil. The average porosity of the Botucatu formation is $33 \%$, and the permeability ranges from 2 to $8 \mathrm{mD}$. The particle size analysis of crushed core (adsorbent) was performed by sifting in sieves of Tyler series. The samples passed through sieve, in which the meshes varied between 10 and 28 mesh. The particles retained in the $-10+14$ mesh sieves were used for the adsorption experiments. The average particle diameter was $1.4 \mathrm{~mm}$, which was calculated by the arithmetic average of the sieve diameter of 10 and 14 mesh.

The specific surface area of adsorbent by Brunauer-Emmett-Teller (BET) analysis was determined by Micromeritics ASAP 2020, by applying $\mathrm{N}_{2}$ physic adsorption at $-195.15^{\circ} \mathrm{C}$. Posteriorly, the samples were degassed at $300{ }^{\circ} \mathrm{C}$ for $30 \mathrm{~min}$ [24]. The chemical analysis of the sandstone samples was carried out by X-ray fluorescence (XRF), Shimadzu, EDX-720.

The experiments concerning the dynamic adsorption were carried out in $200 \mathrm{~mL}$ Erlenmeyer flasks at $28{ }^{\circ} \mathrm{C}, 40{ }^{\circ} \mathrm{C}$ and $60{ }^{\circ} \mathrm{C}$, on a continuously stirred Dubnoff shaker bath for $24 \mathrm{~h}$ to reach equilibrium [20]. Each batch was performed with 8 sample flasks, with constant adsorbent mass of $1 \mathrm{~g}$ and constant volume of $90 \mathrm{~mL}$ of solution, with varying concentrations of surfactant solution and glycerol. Then, after equilibrium had been reached, the mixtures were centrifuged at $3500 \mathrm{rpm}$ for $10 \mathrm{~min}$, then, the limpid solutions above the adsorbent (supernatant) were collected and analyzed.

The adsorption capacity $(\mathrm{q}, \mathrm{mg} / \mathrm{g}$ ) was calculated using Equation (1) by the difference between initial $\left(\mathrm{C}_{0}\right)$ and final (equilibrium) concentration $(\mathrm{Ce})$.

$$
\mathrm{q}=\left(\mathrm{C}_{0}-\mathrm{Ce}\right) \mathrm{V} / \mathrm{W}
$$

where $\mathrm{C}_{0}$ is the initial concentration $(\mathrm{mg} / \mathrm{L}), \mathrm{Ce}$ is the concentration at equilibrium $(\mathrm{mg} / \mathrm{L}), \mathrm{V}$ is the volume of solution used (L), and $\mathrm{W}$ is the weight of adsorbent used (g).

The concentration of surfactant at equilibrium (Ce) was verified using spectrophotometer UV1240, Shimadzu instrument [24]. Wavelength for surfactant in the range of 202-206 nm was initially established through the maximum absorbance found for different concentrations of surfactant used. A calibration curve was primarily established. All tests were performed in pure sandstone, without residual oil in porous media, in conditions that correspond to maximum surfactant adsorption.

In addition, the adsorption tests were carried out under surface conditions, and not subsurface, to ensure that the saponified coconut oil (SCO) ionic surfactant is in maximum adsorption condition, since it is influenced by the increase in temperature (in subsurface).

\subsection{Recovery Test}

Oil recovery tests were performed by fluid flowing into the core-adsorbent (Figure 1). Before the recovery tests, the colors were calcinated at $700{ }^{\circ} \mathrm{C}$ for $18 \mathrm{~h}$ to remove moisture. The surfactant concentration with and without glycerol used in the recovery tests was $80 \%$ above the CMC, in order to guarantee the injection of the solution in the micellar form. 


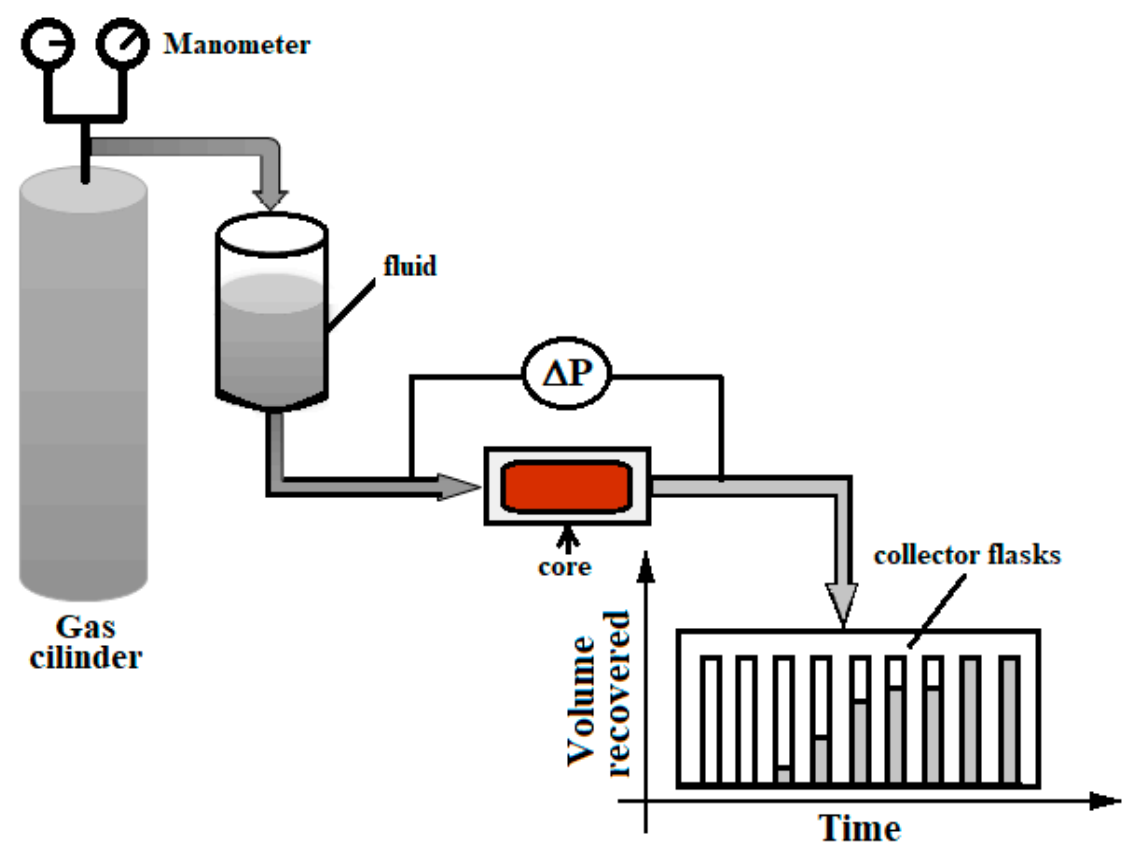

Figure 1. Experimental apparatus for oil recovery.

Oil recovery was performed by brine injection (at $30 \mathrm{psi}$ ) in the counter-current way of oil production, up to reaching the total saturation. After the oil injection phase $(60 / 40$ weight kerosene/petroleum solution), in the same pressure, viscosity of $3.0 \mathrm{cP}$ and density $0.81 \mathrm{~g} / \mathrm{mL}$, at $25^{\circ} \mathrm{C}$ was injected in the current direction of production. The core was flooded with oil until no brine was produced (irreducible water saturation). Residual oil volume in the core was calculated by mass balance. The injection of displaced fluid (EOR method) aimed at recovering residual oil (RO) adhered in the porous media, by decreasing interfacial tensions and applying glycerol/surfactant solution.

The oil recovery factor (RF) was determined by mass balance, shown in Equation (2).

$$
\mathrm{RF}_{\text {total }}=\left(\mathrm{V}_{\text {inj }}-\mathrm{V}_{\text {prod }}\right) * 100 / \mathrm{V}_{\text {inj }}
$$

where $\mathrm{RF}_{\text {total }}$ is the total recovery factor (\%); and $\mathrm{V}_{\text {inj }}$ and $\mathrm{V}_{\text {prod }}$ are the volume injected $(\mathrm{mL})$ and the volume produced $(\mathrm{mL})$, respectively.

Oil samples used in recovery tests were collected from the Ubarana field, Petrobras, located in Guamare, Rio Grande do Norte, Brazil.

\section{Results}

\subsection{Crushed Core Analysis}

The BET surface area of the sandstone sample ranged from 0.0914 to $0.110 \mathrm{~m}^{2} / \mathrm{g}$. The chemical composition of Botucatu sandstone is shown in Table 1. The highest observed concentration was silica $\left(\mathrm{SiO}_{2}\right)$, followed by iron oxide $\left(\mathrm{FeO}_{3}\right)$. These components promote interactions with surfactants molecules and consequently, adsorption on the solid surface.

Thus, this rock has a cationic character, meaning that the anionic surfactants have a greater interaction with this type of sandstone. Cationic surfactants, however, would not present good interaction results with this type of rock [17].

The presence of alumina promotes an interaction of rock with water; hence, there is a need to perform the calcination prior to the water and surfactant solutions injection into the plugs. This substance will enable the formation of the sandstone since it is considered as the cement of the silica grains of the rock. 
Table 1. Chemical composition of Botucatu Sandstone.

\begin{tabular}{cc}
\hline Composition & Concentration (wt. \%) \\
\hline $\mathrm{SiO}_{2}$ & 84.06 \\
$\mathrm{FeO}_{3}$ & 11.72 \\
$\mathrm{Al}_{2} \mathrm{O}_{3}$ & 2.46 \\
$\mathrm{TiO}_{2}$ & 1.27 \\
$\mathrm{ZrO}_{2}$ & 0.34 \\
$\mathrm{CaO}$ & 0.15 \\
\hline
\end{tabular}

The presence of the metal oxides in the rock can also justify a tendency of adsorption of the anionic surfactants in the rock, thus providing the possibility of greater loss of the surfactant from the solution to the rock in the injection process [18].

\subsection{Critical Micelle Concentration (CMC)}

The CMC is an important feature of surfactants, from which it is possible to understand the applications of each surfactant for many uses in the industry. Figure 2 shows the surface tension as a function of the different surfactant concentration for two evaluated solutions, and the CMC can be indicated based on it.

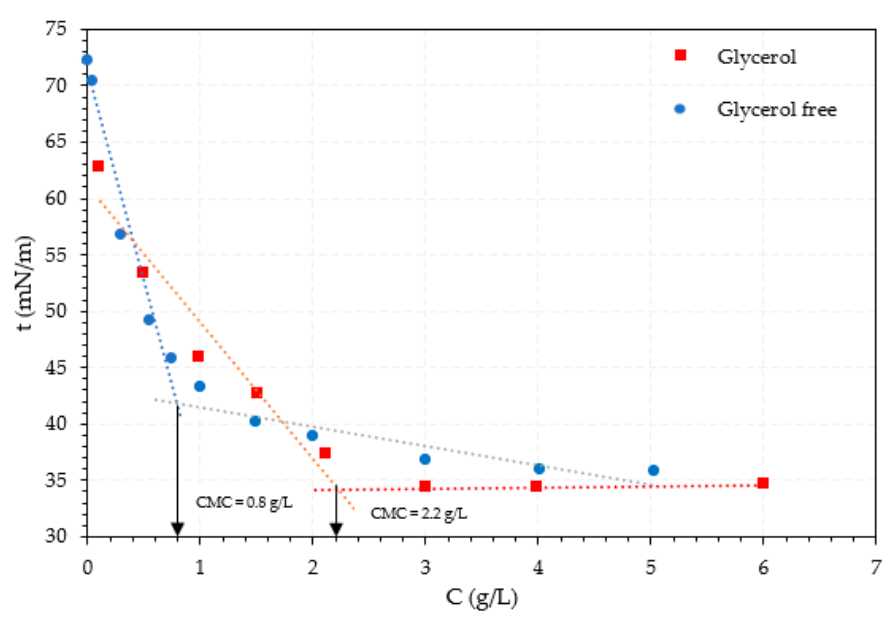

Figure 2. Critical micelle concentration (CMC) for saponified coconut oil (SCO) with and without glycerol, measured by maximum bubble pressure tensiometer.

The critical micelle concentration can be observed at the inflection point of the curve determined by linear fit, according to the Superficial Tension apparatus manual. The lowest tension value of SCO was approximately $35 \mathrm{mN} / \mathrm{m}$, which is much lower than the water surface tension value $(71.99 \pm 0.05 \mathrm{mN} / \mathrm{m})$. The CMC of the SCO, with and without glycerol, are found to be $0.8 \mathrm{~g} / \mathrm{L}$ and $2.2 \mathrm{~g} / \mathrm{L}$, respectively.

When the molecules of the surfactant achieve the CMC, micellar aggregates are formed within the solution, and could decrease the number of hydrated surfactant molecules. However, some molecules, which do not form micelles in the system, will have a higher probability to adsorb in the porous medium. When CMC is achieved, the adsorption of surfactant decreases. Some factors-like electrolytes and additional components in solution and surface type-influence the adsorption form, making different curve shapes of adsorption isotherm [25].

\subsection{Adsorption}

The rock adsorption assays were carried out with the objective of estimating the loss of surfactant in the rock during its injection into the recovery processes. The experiments to evaluate the amount of 
surfactant adsorbed were led at $28^{\circ} \mathrm{C}, 40^{\circ} \mathrm{C}$ and $60^{\circ} \mathrm{C}$, for a particle average size of $-10+14$ mesh $(1.4 \mathrm{~mm})$. The adsorption test lasted $24 \mathrm{~h}$. Subsequently, the absorbance values were read before and after the test, and the calibration curves were done.

Data equilibrium was obtained, which show the variation of equilibrium concentration of the adsorbed phase, $\mathrm{q}$ (mg surfactant/g sandstone), with the concentration of the fluid phase, $\mathrm{Ce}(\mathrm{mg} / \mathrm{L})$, for the surfactant SCO with glycerol (Figure 3) and without glycerol (Figure 4).

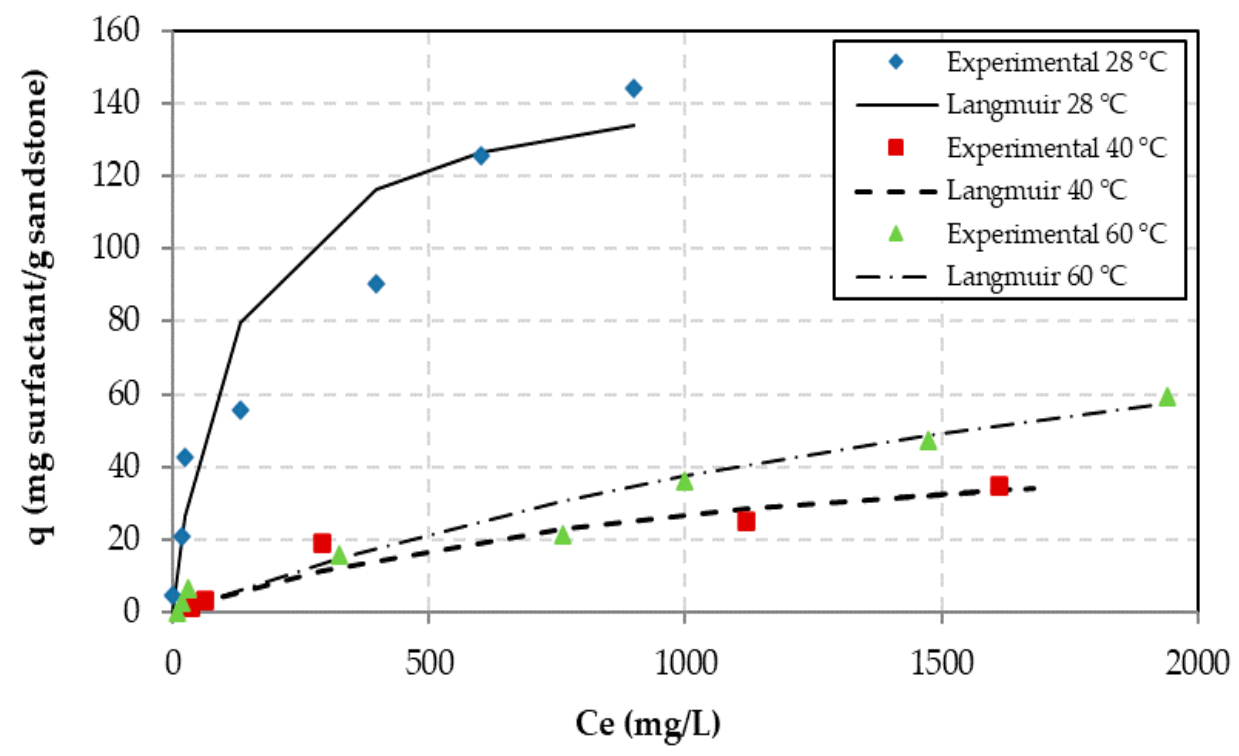

Figure 3. SCO/glycerol adsorption isotherm.

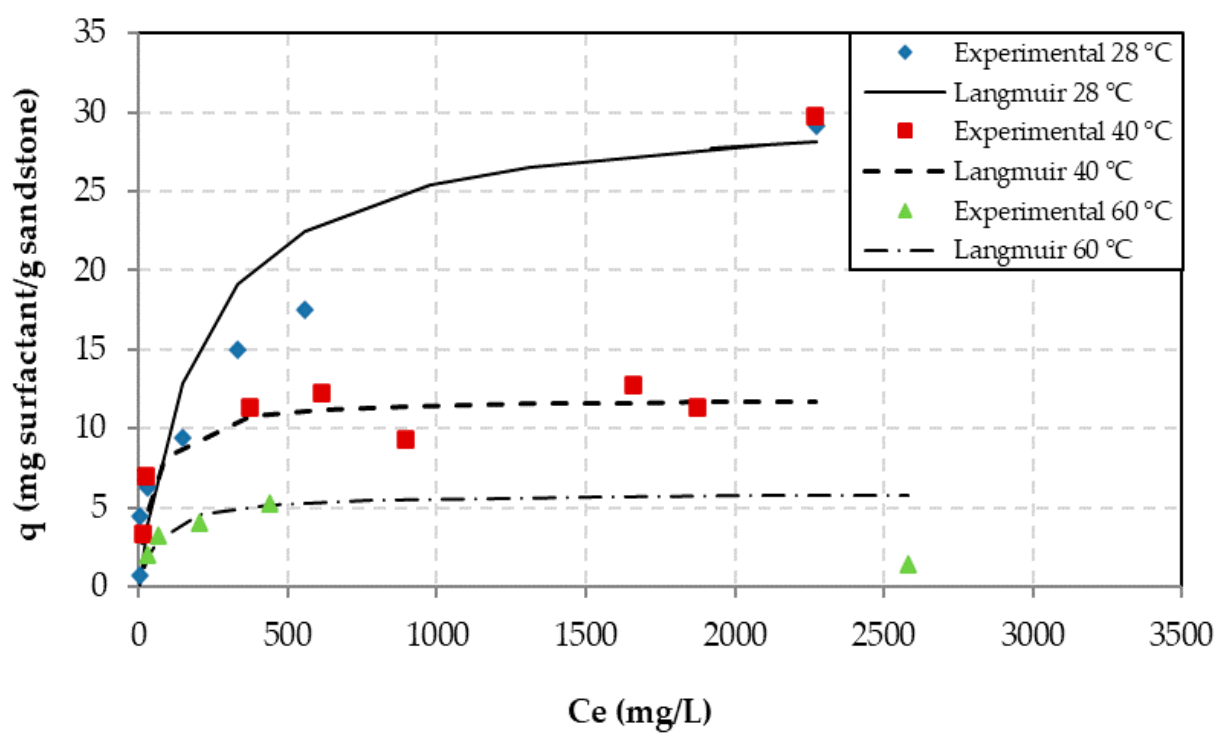

Figure 4. SCO/glycerol free adsorption isotherm.

The isotherms indicated favorable adsorption, because they are an ionic surfactant (anionic) that is charged the opposite to the ions of the sandstone. The electrostatic interactions between the surfactant and the substrate create strong interactions between the surfactant molecules and rock. At a temperature of $28^{\circ} \mathrm{C}$, the highest adsorptive capacity values were observed (Figures 3 and 4), which is, among other factors, due to the exothermic character of the adsorption process. 
The addition of the glycerol to the solution, with the purpose of giving viscosity to the solution and improving the sweep efficiency, increased the adsorption of the adsorbate in the rock, probably due to the increase in the CMC of the solution.

Table 2 shows the models' parameters Equation (3) for the SCO, with and without glycerol at the studied temperatures.

$$
\mathrm{q}_{\mathrm{L}}=\left(\mathrm{k}_{\mathrm{L}} \mathrm{Ce} \mathrm{q}_{\mathrm{m}}\right) /\left(1+\mathrm{k}_{\mathrm{L}} \mathrm{Ce}\right)
$$

where $\mathrm{q}_{\mathrm{L}}$ is the mass of adsorbate adsorbed $(\mathrm{mg} / \mathrm{g}) ; \mathrm{q}_{\mathrm{m}}$ is the maximum mass adsorbed $(\mathrm{mg} / \mathrm{g}) ; \mathrm{k}_{\mathrm{L}}$ is the equilibrium constant (L.m/g); Ce is the equilibrium concentration (mg/L).

Table 2. Langmuir model parameters.

\begin{tabular}{lccc}
\hline \multicolumn{4}{c}{ Solution SCO/Glycerol Free } \\
\hline Parameters & $28{ }^{\circ} \mathrm{C}$ & $40{ }^{\circ} \mathrm{C}$ & $60{ }^{\circ} \mathrm{C}$ \\
$\mathbf{K}_{\mathbf{L}}(\mathbf{L} / \mathbf{m g})$ & 200.00 & 40.00 & 65.20 \\
$\mathbf{q}_{\mathbf{m}} \mathbf{( m g / g )}$ & 30.58 & 11.90 & 5.89 \\
$\mathbf{R}^{\mathbf{2}}$ & 0.96 & 0.97 & 0.98 \\
\hline \multicolumn{4}{c}{ Solution SCO/Glycerol } \\
\hline Parameters & $28{ }^{\circ} \mathrm{C}$ & $40{ }^{\circ} \mathrm{C}$ & $60{ }^{\circ} \mathrm{C}$ \\
$\mathbf{K}_{\mathbf{L}}(\mathbf{L} / \mathbf{m g})$ & 120.48 & 1250.00 & 2500.00 \\
$\mathbf{q}_{\mathbf{m}} \mathbf{( m g / g )}$ & 151.51 & 52.82 & 133.33 \\
$\mathbf{R}^{\mathbf{2}}$ & 0.93 & 0.72 & 0.95 \\
\hline
\end{tabular}

From the Langmuir model parameters (Table 2), it is possible to estimate the amount of surfactant adsorbed, knowing the value of Ce $(\mathrm{mg} / \mathrm{L})$ of the surfactant in the solution, $\mathrm{q}_{\mathrm{L}}(\mathrm{mg} / \mathrm{g})$ can be calculated using Equation (3), and knowing the amount of sandstone (adsorbent), the amount of adsorbed surfactant is consequently estimated.

The Langmuir isotherm is most recommended for monolayer adsorption. Thereby, a significant constant of this model is the parameter $\mathrm{R}_{\mathrm{L}}$, which is a no dimensional constant known as separation factor [26]. The $\mathrm{R}_{\mathrm{L}}$ values obtained for the adsorption study with and without glycerol are shown in Table 3.

Table 3. Data $\mathrm{R}_{\mathrm{L}}$ (separation factor) for adsorption with and without glycerol.

\begin{tabular}{ccc}
\hline Temperature $\left({ }^{\circ} \mathbf{C}\right)$ & $\left.\mathbf{( R}_{\mathbf{L}}\right)$ without Glycerol & $\left.\mathbf{( R}_{\mathbf{L}}\right)$ Glycerol \\
\hline 28 & $0.0712-0.9522$ & $0.0459-0.9232$ \\
40 & $0.0152-0.4445$ & $0.4015-0.9918$ \\
60 & $0.0235-0.8621$ & $0.6466-0.9961$ \\
\hline
\end{tabular}

Table 3 shows that the values obtained for the separation factor at temperatures of $28^{\circ} \mathrm{C}, 40^{\circ} \mathrm{C}$ and $60^{\circ} \mathrm{C}$, mainly at $28{ }^{\circ} \mathrm{C}$, indicate a favorable adsorption $\left(0<\mathrm{R}_{\mathrm{L}}<1\right)$, proving the exothermic nature of the process of adsorption.

\subsection{Recovery and Estimating Loss of Surfactant}

The amount of adsorbate (surfactant) adsorbed per mass of sandstone until reaching bed saturation was obtained from Equation (3), data from Figures 3 and 4, and Table 2 at a temperature of $28^{\circ} \mathrm{C}$. Results show that, for $1 \mathrm{~g}$ of sandstone, $30.58 \mathrm{mg}$ and $151.51 \mathrm{mg}$ of surfactant were lost to the SCO/glycerol free and SCO/glycerol systems, respectively. The bed column was composed by $22 \mathrm{~g}$ of sandstone, whereby approximately $0.7 \mathrm{~g}$ and $3.3 \mathrm{~g}$ of surfactant were lost by adsorption during the tests. In addition, the value of $\mathrm{q}_{\mathrm{L}}$ found in Figures 3 and 4, at the concentrations of $720 \mathrm{mg} / \mathrm{L}$ (with and without glycerol) are close to those of $24 \mathrm{mg}$ and $136 \mathrm{mg}$ of surfactant/g of sandstone, showing that the fit is consistent.

The volume of original oil in place (OOIP) for glycerol-free/surfactant and glycerol/surfactant solutions were $6.8 \mathrm{~mL}$ and $6.9 \mathrm{~mL}$, respectively. The volume of $1.2 \mathrm{~mL}$ and $2.3 \mathrm{~mL}$ of oil were 
recovered from those solutions, respectively. Surfactant loss by adsorption in the recovery test for the glycerol-free/surfactant solution was low, approximately $12.3 \%$ of surfactant, presenting low oil recovered of $18 \%$. Concerning the recovery in the glycerol/surfactant solution, the surfactant adsorption was approximately $49 \%$ higher, however, it recovered 33\% more, according to Borges [27], who obtained an oil recovery factor for glycerol of $35 \%$. These results refer only to the EOR method. This represents a good percentage, since about $30 \%$ of oil recovery can be obtained in the conventional method [28].

The higher adsorption for the solution of surfactant with glycerol is due to the increase of the amount of surfactant in the solution to reach the CMC. Consequently, the adsorbed surfactant took the place of the oil present in the sandstone (wettability inversion), recovering a larger quantity of oil, which was also due to improving oil sweep efficiency caused by the presence of the glycerol that acted as a viscosifier of the solution.

The estimated loss of surfactant (adsorption) was measured at the temperature of $28^{\circ} \mathrm{C}$, where the highest losses occurred. The reservoir temperature was approximately $55^{\circ} \mathrm{C}$, and it could be possible to minimize the adsorption and increase the recovery factor using surfactant/glycerol solution.

Finally, the surfactant solution with glycerol may prove to be a good chemical agent (mixture) to the EOR method. In addition, the SCO surfactant is available at a low cost, and it is biodegradable, as is the glycerol, a byproduct of biodiesel.

\subsection{Viscosity}

To obtain good sweeping and displacement efficiencies, a low mobility ratio, which is a rate between oil viscosity and injected solution $\left(\mathrm{M}=\mu_{\text {oil }} / \mu_{\text {solution }}\right)$, is required, i.e., close to one, considering that the relative permeabilities of each fluid (oil and solution) are almost equal. In this case, the injected fluid (displacement phase) will develop viscous fingering (displaced fluid), and will create preferential paths between the injecting and producing wells.

The use of polymer to provide viscosity to the displacing fluid or steam injection to reduce oil viscosity is a common enough activity for the process to be controlled [6]. Figure 5 shows that the average viscosity of the surfactant solution increased from $0.5 \mathrm{cP}$ to $1.5 \mathrm{cP}$ by incorporating glycerol in the solution, approaching oil viscosity (average value of $1.9 \mathrm{cP}$ ). The solution showed Newtonian fluid behavior, according to Qiu [29], and a mobility ratio of 1.26 .

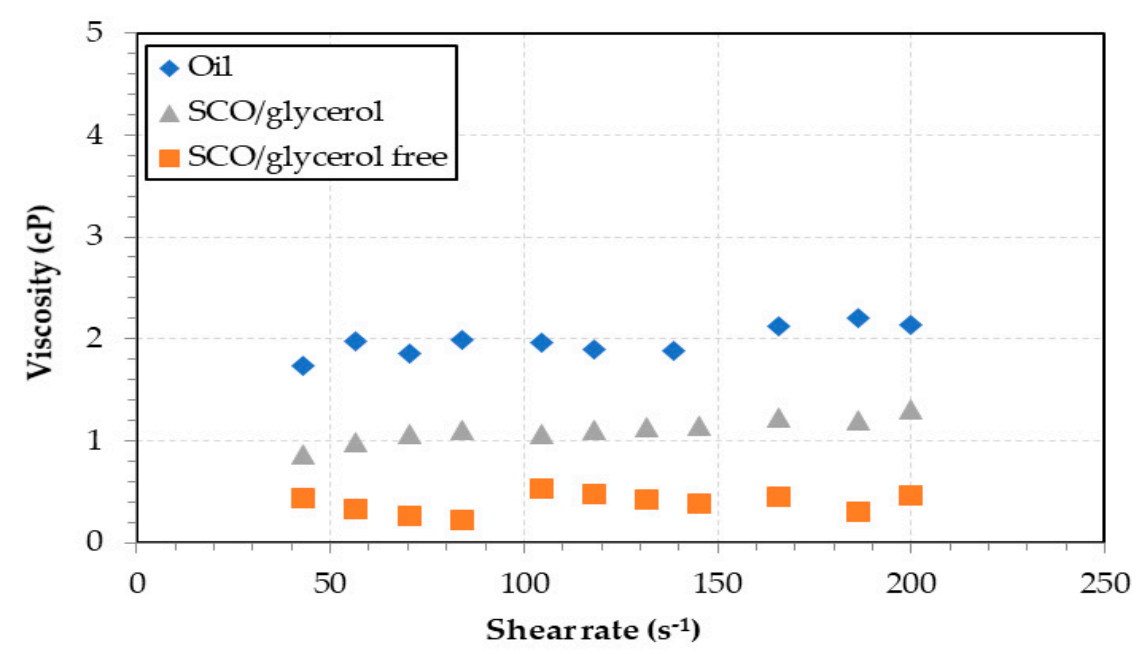

Figure 5. Viscosity of petroleum, SCO/glycerol, and SCO/glycerol free, at $55^{\circ} \mathrm{C}$.

\subsection{Thermal Study}

Figure 6 shows the thermogravimetric curves (TG) of the studied samples: SCO, glycerol, surfactant solution with and without glycerol. 


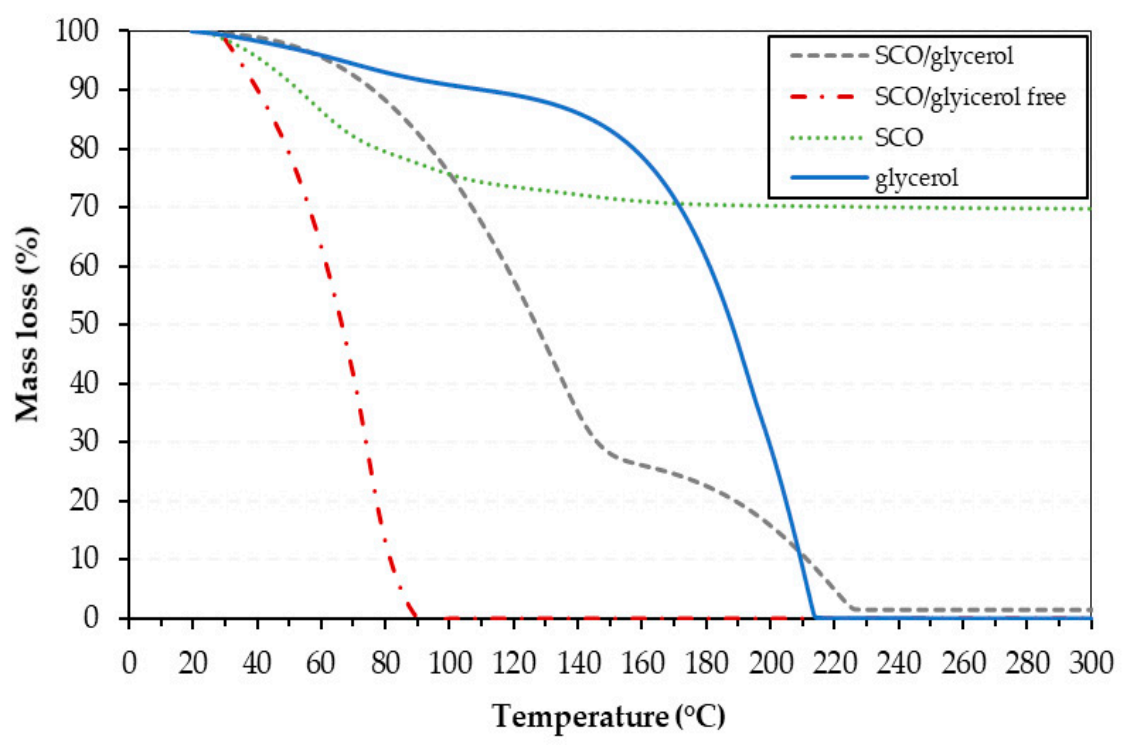

Figure 6. Thermogravimetric curves (TG) curves of studied samples.

Little mass loss of glycerol and glycerol/SCO solution were observed for the adopted temperature range $\left(55-60^{\circ} \mathrm{C}\right.$ ) (Figure 6), approximately $3.6 \%$, for both. For SCO, at the same temperature, the loss was approximately $11.3 \%$, and glycerol-free/SCO solution, $28 \%$. This is because the surfactant/glycerol free solution presents in its composition plenty of water.

\section{Conclusions}

The main objective of this work was to study the effect of glycerol on surfactant adsorption in sandstones and on EOR in SCO ionic surfactant solution. From the results it was concluded that: (1) the Langmuir adsorption model represented adequate equilibrium data, showing monolayer adsorption; (2) the viscosity of the SCO surfactant/glycerol solution was close to oil, and good mobility ratios could be obtained, with good sweeping and displacement efficiencies, due to the presence of glycerol; (3) glycerol increased surfactant adsorption, however higher recovery factors were obtained for the glycerol/SCO solution, being $53 \%$ higher than the glycerol free surfactant solution. The surfactant loss was slightly higher for the glycerol surfactant solution (49\%), but recovered more oil (33\%); (4) higher oil removal (displaced fluid) was achieved when glycerol was added to the surfactant solution (displacing fluid), because of better sweep efficiencies caused by increasing the solution's viscosity.

\section{Patents}

This research work generated an invention patent entitled: Glycerol and saponified coconut oil (ionic surfactant) as a displacing fluid to increase oil recovery (In Portuguese). Registration number: BR1020170214435, Registration at INPI-Instituto Nacional da Propriedade Industrial. Deposite date: 10/06/2017.

Author Contributions: In this study, authors F.D.S.C., A.I.C.G., D.F.Q.L., A.B.C., R.R.S., E.M.P. contributed equally to each section of this paper. All authors have read and agreed to the published version of the manuscript.

Funding: This research received no external funding.

Acknowledgments: The authors thank to FAPESQ/CAPES and PIBIC/CNPq/UFPB by scholarship granted (no number), and Postgraduate Program of Chemical Engineering/PPGEQ/UFPB.

Conflicts of Interest: The authors declare no conflict of interest. 


\section{References}

1. Lakatos, I.; Lakatos-Szabó, J. Global oil demand and role of chemical EOR methods in the 21st century. Int. J. Oil Gas Coal Technol. 2008, 1, 46-64. [CrossRef]

2. Park, S.; Lee, E.S.; Sulaiman, W.R.W. Adsorption behaviors of surfactants for chemical flooding in enhanced oil recovery. J. Ind. Eng. Chem. 2015, 21, 1239-1245. [CrossRef]

3. Wang, J.; Han, M.; Fuseni, A.B.; Cao, D. Surfactant adsorption in surfactant-polymer flooding for carbonate reservoirs. Middle East Oil Show 2015. [CrossRef]

4. Zhang, J.; Wang, D.; Olatunji, K. Surfactant Adsorption Investigation in Ultra-Lower Permeable Rocks. SPE Low Perm Symp. 2016. [CrossRef]

5. Thomas, J.E. Fundamentals of Petroleum Engineering; Interciência: Rio de Janeiro, Brzail, 2001; ISBN 8571930465. (In Portuguese)

6. Raffa, P.; Broekhuis, A.A.; Picchioni, F. Polymeric surfactants for enhanced oil recovery: A review. J. Pet. Sci. Eng. 2016, 145, 723-733. [CrossRef]

7. Zhang, R.; Somasundaran, P. Advances in adsorption of surfactants and their mixtures at solid/solution interfaces. Adv. Colloid Interface Sci. 2006, 123, 213-229. [CrossRef]

8. Hanamertani, A.S.; Pilus, R.M.; Idris, A.K.; Irawan, S.; Tan, I.M. Ionic liquids as a potential additive for reducing surfactant adsorption onto crushed Berea sandstone. J. Pet. Sci. Eng. 2018, 162, 480-490. [CrossRef]

9. Nourafkan, E.; Hu, Z.; Wen, D. Nanoparticle-enabled delivery of surfactants in porous media. J. Colloid Interface Sci. 2018, 519, 44-57. [CrossRef]

10. Wu, Y.; Chen, W.; Dai, C.; Huang, Y.; Li, H.; Zhao, M.; He, L.; Jiao, B. Reducing Surfactant Adsorption on Rock by Silica Nanoparticles for Enhanced Oil Recovery. J. Pet. Sci. Eng. 2017, 153, 283-287. [CrossRef]

11. Budhathoki, M.; Barnee, S.H.R.; Shiau, B.J.; Harwell, J.H. Improved oil recovery by reducing surfactant adsorption with polyelectrolyte in high saline brine. Colloids Surfaces A Physicochem. Eng. Asp. 2016, 498, 66-73. [CrossRef]

12. Venter, A.C. Glycerol Compositions and Solutions. Patent WO 176151, 27 December 2012.

13. Pagliaro, M.; Rossi, M. New usages for a versatile raw material. In The Future of Glycerol; RSC Publishing: London, UK, 2008. [CrossRef]

14. Takamura, K.; Fischer, H.; Morrow, N.R. Physical properties of aqueous glycerol solutions. J. Pet. Sci. Eng. 2012, 98, 50-60. [CrossRef]

15. Ferreira, G.F.D.; Souza, D.R.Q.; Lima, R.; Lobato, A.K.C.L.; Silva, A.C.M.; Santos, L.C.L. Novel glycerol-based microemulsion formulation for enhanced oil recovery. J. Pet. Sci. Eng. 2018, 167, 674-681. [CrossRef]

16. Hosseini-Nasab, S.M.; Zitha, P.L.J.; Mirhaj, S.A.; Simjoo, M. A new chemical-enhanced oil recovery method. Colloids Surfaces A Physicochem. Eng. Asp. 2016, 507, 89-95. [CrossRef]

17. Curbelo, F.D.S.; Garnica, A.I.C.; Barros Neto, E.L. Enhanced Oil Recovery and Adsorption of Ionic Surfactant. Pet. Sci. Technol. 2013, 7, 663-671. [CrossRef]

18. Santos, F.K.G.; Barros Neto, E.L.; Moura, M.C.P.; Castro Dantas, T.N.; Dantas Neto, A.A. Molecular behavior of ionic and nonionic surfactants in saline medium. Colloids Surfaces A Physicochem. Eng. Asp. 2009, 333, 156-162. [CrossRef]

19. Majeed, T.; Solling, T.; Kamal, M.S. Foamstability: The interplay between salt-, surfactant- and critical micelle concentration. J. Pet. Sci. Eng. 2020, 187, 106871. [CrossRef]

20. Yekeen, N.; Padmanabhan, E.; Idrisb, A.K.; Ibad, S.M. Surfactant adsorption behaviors onto shale from Malaysian formations: Influence of silicon dioxide nanoparticles, surfactant type, temperature, salinity and shale lithology. J. Pet. Sci. Eng. 2019, 179, 841-854. [CrossRef]

21. Neves, A.M.; Santanna, V.C.; Barillas, J.L.M.; Dantas, T.N.C.; Góis, A.G.B. Ionic surfactants applied in enhanced oil recovery: Adsorption, imbibition, and zeta potential approaches. Braz. J. Chem. Eng. 2019. [CrossRef]

22. Alameri, W.; Teklu, T.W.; Graves, R.M.; Kazemi, H.; AlSumaiti, A.M. Low-salinity water-alternatesurfactant in Low-permeability Carbonate Reservoirs. In Proceedings of the 18th European Symposium on Improved Oil Recovery Conference, Dresden, Germany, 14-16 April 2015. [CrossRef]

23. Zhang, J.; Wang, D.; Butler, R. Optimal Salinity Study to Support Surfactant Imbibition into the Bakken Shale. In Proceedings of the SPE Unconventional Resources Conference Canada, Calgary, AB, Canada, 5-7 November 2013. 
24. Saxena, N.; Kumar, A.; Mandal, A. Adsorption analysis of natural anionic surfactant for enhanced oil recovery: The role of mineralogy, salinity, alkalinity and nanoparticles. J. Pet. Sci. Eng. 2019, 173, 1264-1283. [CrossRef]

25. Lv, W.; Bazin, B.; Ma, D.; Liu, Q.; Han, D.; Wu, K. Static and dynamic adsorption of anionic and amphoteric surfactants with and without the presence of alkali. J. Pet. Sci. Eng. 2011, 77, 209-218. [CrossRef]

26. Bera, A.; Kumar, T.; Ojha, K.; Mandal, A. Adsorption of surfactants on sand surface in enhanced oil recovery: Isotherms, kinetics and thermodynamic studies. Appl. Surf. Sci. 2013, 284, 87-99. [CrossRef]

27. Borges, S.M.S. Enhanced Oil Recovery (EOR) Using Glycerol by Biodiesel Production. Ph.D. Thesis, Federal University of Bahia, Salvador, Brazil, 2009. (In Portuguese).

28. Mandal, A. Chemical flood enhanced oil recovery: A review. Int. J. Oil Gas Coal Technol. 2015, 9, $241-264$. [CrossRef]

29. Qiu, F. The Potential Applications in Heavy Oil EOR with the Nanoparticle and Surfactant Stabilized Solvent-Based Emulsion. In Proceedings of the Canadian Unconventional Resources and International Petroleum Conference, Calgary, AB, Canada, 19-21 October 2010. [CrossRef]

(C) 2020 by the authors. Licensee MDPI, Basel, Switzerland. This article is an open access article distributed under the terms and conditions of the Creative Commons Attribution (CC BY) license (http://creativecommons.org/licenses/by/4.0/). 